\title{
PREDICATES OF PERSONAL TASTE IN COMMUNICATION: A CASE OF DISAGREEMENT ${ }^{1}$
}

\author{
MARIÁN ZOUHAR \\ Faculty of Arts, Comenius University in Bratislava
}

ZOUHAR, Marián: Predicates of personal taste in communication: A case of disagreement. Journal of Linguistics, 2018, Vol. 69, No 1, pp. 25 - 38.

\begin{abstract}
The aim of the paper is to defend the idea that, from the semantic point of view, predicates of personal taste behave in communication like ordinary indexical expressions (pronouns, demonstratives, etc.). It means that they express different semantic contents relative to relevantly different contexts of utterances. This is a consequence of the claim that "tasty" (which is our paradigm example of a predicate of personal taste) and "tasty for (someone)" (where "someone" is a placeholder for an agent) express the same, or very similar, semantic contents relative to the same context of utterance. Now this idea can be challenged by pointing to certain communicative phenomena, such as disagreements about matters of personal taste. It is argued, however, that there is an explanation of taste disagreements that is compatible with the indexical nature of predicates of personal taste. Moreover, it is shown that an explanation along these lines is rather natural because it seems to be necessitated by communication-based evidence.
\end{abstract}

Key words: doxastic disagreement, indexical expression, non-doxastic disagreement, predicate of personal taste, requisite

\section{INTRODUCTION}

Compare the following situations in which speaker $B$ responds to an utterance produced by speaker $A$. In a Type I situation, $A$ utters "Spinach is tasty" and $B$ replies with uttering "Spinach is not tasty"; in a Type II situation, $A$ utters "Spinach is tasty for me" and $B$ replies with uttering "Spinach is not tasty for me". Intuitively, we would say that the Type I situation involves disagreement between $A$ and $B$ while the Type II situation does not. This intuition can be strengthened by adding that $B$ may respond to $A$ 's utterance of "Spinach is tasty" with "That is false, spinach is not tasty" in the former situation, indicating thus that what $A$ said was not true; on the other hand, responding "That is false, spinach is not tasty for me" to $A$ 's utterance of "Spinach is tasty for me" would be inappropriate for $B$ in the latter situation.

\footnotetext{
${ }^{1}$ This paper was supported by VEGA grant No. 1/0036/17.
} 
The disagreement-based difference between the two types of situation clearly suggests that utterances of "Spinach is (not) tasty" and "Spinach is (not) tasty for me" have to express different kinds of semantic content. In particular, the semantic content of "tasty" must be different from the semantic content of "tasty for (someone)". If a person says about something that it is tasty, the subject-matter of her claim consists in ascribing a certain property to the thing under discussion; if a person says about something that it is tasty for her, however, the subject-matter of her claim consists in ascribing a certain relation to a pair of items that contains the thing in question and the person. As a result, it must be clear that utterances of "Spinach is (not) tasty" and "Spinach is (not) tasty for me" are used to communicate different kinds of information.

This conclusion can be claimed to undermine all semantic theories according to which the semantic content of "tasty" (relative to a context of utterance) is tantamount to, or even identical with, the semantic content of "tasty for (someone)" (relative to the same context of utterance). Predicates of personal taste like "tasty", "disgusting", "delicious", etc. and other evaluative predicates like "funny", "boring", "exciting", etc. are thus supposed to be semantically different from indexical-like predicates such as "tasty for (someone)". In sum, predicates of personal taste like "tasty" (and other evaluative predicates) are claimed not to be (on a par with) indexical-like predicates. Semanticists should take this fact into account when suggesting semantic theories of predicates of personal taste (and evaluative predicates in general). ${ }^{2}$

My aim in this paper is to undermine this kind of reasoning. I am going to defend the idea that "tasty" and "tasty for (someone)" are used to express the same semantic content. It means that predicates of taste like "tasty" are best viewed as indexical because they involve a hidden indexical reference to an agent-usually, the agent is identical with the person who utters the expression in question, but it is easy to imagine that the agent is someone else (a hearer, a third party or a whole group of people). Given the previous considerations, such a view can be defended

${ }^{2}$ The argument from disagreement about matters of personal taste belongs to crucial arguments that are invoked in the debate between relativists and contextualists (with respect to predicates of personal taste). Generally speaking, contextualists claim that "tasty" means (roughly) the same as "tasty for (someone)" (this is a grave oversimplification because there are widely different kinds of contextualist theories, but for the present purposes the differences between them can be ignored), and relativists invoke the argument to show that this is not the case and, thus, that contextualism fails to be a general semantic theory. Relativist theories are presented, most notably, in Kölbel (2002), Lasersohn (2005), MacFarlane (2014), Richard (2008), and Wright (1992) (although MacFarlane does not label his theory "relativism"). Contextualist theories are proposed by Glanzberg (2007), Huvenes (2012), Marques \& García-Carpintero (2014), Schaffer (2011), and Silk (2016), to name just a few. The prospects of the argument from disagreement as regards its power to undermine contextualism is critically discussed in Gutzmann (2016), Huvenes (2012), López de Sa (2008), Marques \& García-Carpintero (2014), Sundell (2011), and Zouhar (2018). 
only provided one is able to show that, appearances notwithstanding, the initial Type I situation is rather close to the Type II situation. This is precisely what I try to do in this paper.

\section{TWO KINDS OF DISAGREEMENT ABOUT TASTE}

To begin with, let us ponder a bit upon the kinds of disagreement illustrated by the initial Type I and Type II situations. It is rather intuitive to say that if $B$ responds "That is false, spinach is not tasty" to $A$ 's utterance of "Spinach is tasty" in the Type I situation, $B$ intends to reject the proposition expressed by $A$ 's utterance. This explanation seems to be on the right track - since $A$ can be said to express the proposition that spinach is tasty and $B$ endorses the negation of this proposition, namely the proposition that spinach is not tasty, $B$ may appropriately prefix his utterance of "Spinach is not tasty" by "That is false", indicating thus that he takes $A$ 's proposition as false. ${ }^{3}$ An utterance of "That is false" is a straightforward means for $B$ to make obvious his intention to reject $A$ 's proposition.

An analogous explanation cannot be applied to the Type II situation in which $B$ utters "Spinach is not tasty for me" in response to $A$ 's utterance of "Spinach is tasty for me". Since the proposition that spinach is not tasty for $B$ is not a negation of the proposition that spinach is tasty for $A, B$ cannot be interpreted as rejecting $A$ 's proposition; the two propositions are perfectly compatible with each other, and both of them can be simultaneously true. That is why it does not make sense for $B$ to prefix his utterance of "Spinach is not tasty for me" by "That is false". If $B$ uttered "That is false" instead of "Spinach is not tasty for me", he would express the proposition that it is not the case that spinach is tasty for $A$. It is clear that this is not what $B$ intends to communicate.

Now if it were the case that utterances of "Spinach is (not) tasty" and "Spinach is (not) tasty for me" were semantically on a par, this problem would also hold for Type I situations - it would be impossible to interpret the situation in which $B$ utters "Spinach is not tasty" in response to $A$ 's utterance of "Spinach is tasty" as a case of expressing a proposition that is incompatible with $A$ 's proposition, and thus as rejecting $A$ 's proposition. This would be an unacceptable result because it conflicts with ordinary observation of our communicative practice. That is why the two kinds of utterances must not be viewed to be semantically on a par.

\footnotetext{
${ }^{3}$ Propositions are understood here as extra-linguistic (abstract) entities that are semantic contents of utterances of indicative sentences. Propositions are primary bearers of truth values and they also are primary targets of propositional attitudes (such as believing, presupposing, doubting, etc.). There are tons of different theories of propositions available in the philosophical literature, but I do not assume any of the theories in this paper because the subsequent considerations are rather independent of them. Nonetheless, I adopt the usual italicized way of marking propositions: an utterance of an indicative sentence, " $p$ ", expresses the proposition that $p$ (always written in italics).
} 
This conclusion is based on the fact that it is appropriate to use "That is false" by way of rejecting someone's proposition and that this locution, though available as an appropriate response to utterances of "Spinach is tasty", is unavailable as a suitable response to utterances of "Spinach is tasty for me" ${ }^{4}$ It should be observed, however, that there is a multitude of dissent phrases and that some of them might appear to be quite appropriate in situations in which "That is false" is felt to be inappropriate. This observation bears important consequences with respect to the very idea of expressing disagreement regarding matters of taste.

Instead of saying "That is false", one may utter "No", "I disagree", "I do not share your attitude", and "You are mistaken", to give just a few notable examples. No doubt, at least some of these locutions can be used to supplement $B$ 's utterance of "Spinach is not tasty for me" that is used as a respond to $A$ 's utterance of "Spinach is tasty for me". For example, responding "I do not share your attitude, spinach is not tasty for me" is perfectly legitimate. In saying so, $B$ declares his disagreement with the utterer of "Spinach is tasty for me". Nevertheless, it is clear that, in saying so, $B$ actually does not reject $A$ 's proposition, i.e. the proposition that spinach is tasty for $A$. $B$ may both admit that this proposition is true, because he believes that $A$ really does find spinach tasty for her, and still disagree with $A$ about the tastiness of spinach. Thus, if it is possible for $B$ to disagree with $A$ along these lines, a different kind of disagreement has to be invoked. If the Type II situation is interpreted as involving $B$ 's disagreement with $A$, it must be a different kind of disagreement than the one contained in the Type I situation.

The kind of disagreement illustrated by the Type II situation can be approached in the following way. It is instructive to notice that $B$ may respond to $A$ by uttering "I do not share your attitude", for example. In so saying, $B$ makes two things clear that he understands $A$ 's utterance as a manifestation of a certain attitude toward spinach and that he refuses to adopt the same attitude toward spinach as $A$. Thus, though not expressing disagreement with $A$ 's proposition - according to which $A$ bears the attitude of liking towards the taste of spinach $-B$ expresses his disagreement with $A$ 's attitude toward spinach by manifesting an incompatible attitude of disliking toward the taste of spinach. ${ }^{5}$ The result is that disagreements

\footnotetext{
${ }^{4}$ Strictly speaking, there are situations in which it is quite appropriate to respond "That is false" to an utterance of "Spinach is tasty for me". If a speaker utters "Spinach is tasty for me" and the audience recognizes that the speaker lies, for example, the audience may appropriately respond with "That is false", meaning to say that it is not the case that spinach is tasty for the speaker. Given that situations of this kind are irrelevant to the present discussion, I ignore them in the paper.

${ }^{5}$ The notion of incompatibility applied to attitudes (rather than propositions or sentences) is supposed to be identical with the notion of non-cotenability, as defined by MacFarlane (2014, p. 121). Roughly speaking, one attitude is non-cotenable with another attitude provided a rational agent who takes the former attitude toward something cannot take the latter attitude toward the same thing without changing her mind.
} 
regarding attitudes have to be distinguished from disagreements regarding propositions. It is easy to see that in the case of factual discourse that concerns the pursuit of truth, the latter kind of disagreement is crucial; on the other hand, in the case of evaluative discourse in which people are primarily concerned with attributing various kinds of values to items, the former kind of disagreement may prevail. Disagreement concerning propositions is usually called doxastic disagreement and disagreement concerning attitudes is often called non-doxastic disagreement. ${ }^{6}$ In the case of disputes that concern taste and related matters, people usually disagree with one another in the non-doxastic sense.

\section{GENERALIZATION}

The above suggestion to view disagreements about taste as non-doxastic is appropriate to Type II situations. Based on this, Type II situations either involve no disagreement at all or involve non-doxastic disagreements in which speakers disagree with one another because of bearing different evaluative attitudes toward the same thing. ${ }^{7}$ Now it might be asked whether it is possible to generalize the idea of nondoxastic disagreement to Type I situations. This generalization may take two forms either the form of admitting that Type I situations are capable to harbor both doxastic and non-doxastic disagreements or the form of suggesting that Type I situations feature only non-doxastic disagreements and thus what appears to be a doxastic disagreement is actually an instance of non-doxastic disagreement in disguise. It seems that Type I situations can be explained as containing doxastic disagreements because it is rather intuitive to understand exchanges of this kind as containing rejections of propositions rather than rejections of attitudes. If, contrary to appearances, Type I situations contained non-doxastic rather than doxastic disagreements, it would be necessary to explain away the impression that $B$ 's response to $A$ in the initial Type I situation was intended to rebut the proposition $A$ expressed by her utterance.

I am going to argue that Type I situations do involve non-doxastic rather than doxastic disagreements, and that the impression that they harbor doxastic disagreements is an illusion that is prompted by a specific form of sentences that are used in Type I situations. There are two kinds of argument that can be used to justify

${ }^{6}$ In the modern philosophical literature, the distinction between doxastic and non-doxastic disagreement (and its variants) is widely recognized in metaethics and related evaluative domains since the appearance of Stevenson (1937). The distinction is widely employed by theories that distinguish between assertive (or truth-conditional) dimension of evaluative utterances (broadly conceived) and expressive (or affective, non-truth-conditional) dimension of evaluative utterances. The most interesting applications to the discourse about taste can be found in Buekens (2011), Clapp (2015), Gutzmann (2016), Huvenes (2012), and - at least to a certain extent - Egan (2014) and Marques and GarcíaCarpintero (2014).

${ }^{7}$ If the first option arises, speakers merely inform each other about their attitudes toward tastes of particular objects without expressing any stance regarding the other speaker's attitude. 
the idea that Type I situations contain non-doxastic disagreements. One kind of argument is broadly philosophical, and I outline it in a somewhat broad strokes. The other kind of argument is based on our linguistic practice, and I give some examples of this practice.

First, let us make some philosophy. The philosophical argument consists in that being tasty and not being tasty are not ordinary properties. As a result, it makes no good sense to say that objects instantiate such properties, and that people may ascribe them to objects. In particular, spinach is described as instantiating tastiness in the sentence uttered by $A$ and as not instantiating tastiness in the sentence uttered by $B$. Now it is clear that things are tasty only provided there is someone for whom they are tasty. It does not make sense to say that being tasty is an absolute property like being human. ${ }^{8}$ The latter property is absolute because objects instantiate it regardless of any further condition; the former property, however, is instantiated by objects only relative to further conditions such as standards of taste of a particular person. ${ }^{9}$ If $A$ sincerely says that spinach is tasty, she ascribes tastiness to spinach on the basis of her standards of taste, and if $B$ responds with a sincere assertion that spinach is not tasty, he refuses to ascribe tastiness to spinach on the basis of his standards of taste. This fact can be interpreted as implying that there actually are no full-blooded properties like being tasty and not being tasty; instead, there are properties like being tasty for $A$ and not being tasty for $B$ - the latter properties can be instantiated by objects regardless of any other conditions. ${ }^{10}$ Now if this interpretation is accepted, it should also be accepted that when $A$ utters "Spinach is tasty", she ends up expressing the proposition that spinach is tasty for $A$, and, similarly, when $B$ responds with uttering "Spinach is not tasty", he expresses the proposition that spinach is not tasty for $B$. This result can be used to show that $B$ 's response to $A$ 's utterance in the initial Type I situation can hardly be interpreted as containing an instance of doxastic disagreement with $A$ - having expressed the proposition that spinach is not tasty for $B, B$ cannot be viewed as rejecting the proposition expressed by $A$ 's utterance. Nevertheless, the very fact that $B$ does disagree with $A$ prompts us to say that his disagreement is non-doxastic.

Second, some evidence for assuming that the disagreement contained in Type I situations is of the non-doxastic variety can be derived from our ordinary

${ }^{8}$ I use italics to mark properties (in the same sense as italics is used to mark propositions).

${ }^{9}$ Strictly speaking, being human is a contingent property that can be instantiated by objects relative to modal and temporal parameters (i.e. relative to possible worlds and times). All contingent properties are of this kind. Evaluative properties like being tasty are not contingent in this sense, because specifying a possible world and time does not suffice to determine whether an object instantiates it or not. Thus, some other parameters have to be taken into account. It is this difference between contingent properties and evaluative properties that I allude to in the main text.

${ }^{10}$ Or, using a more appropriate formulation, objects instantiate them only relative to modal and temporal parameters. 
communicative practice. This kind of evidence can be made more persuasive if we also consider the case of agreement for illustrative purposes. Agreement is a dual notion with respect to the notion of disagreement, and as one may interpret disagreements about matters of taste as being of the non-doxastic variety so one may interpret agreements about matters of taste as also being non-doxastic. In what follows, four different pieces of evidence are outlined.

First, let us compare the typical exchanges (1) and (2) in which $B$ expresses his (dis)agreement with $A$, and some slightly modified exchanges to be specified later on:

(1) $A$ : Spinach is tasty.

$B$ : I disagree. Spinach is not tasty.

(2) $A:$ Spinach is tasty.

$B$ : I agree. Spinach is tasty.

Clearly, (1) contains $B$ 's disagreement with $A$ and (2) contains $B$ 's agreement with $A$. $B$ makes this obvious by introducing his respective lines with "I disagree" and "I agree". Of course, if their utterances express the enriched propositions that spinach is tasty for $A$ and that spinach is (not) tasty for $B$, respectively, $B$ cannot be said to (dis)agree with $A$ in the doxastic sense. Is his (dis)agreement non-doxastic instead? I think it is because the effect achieved by the exchanges involved in (1) and (2) can also be achieved when $B$ responds a bit differently. Instead of (2), we might have:

(3) $A$ : Spinach is tasty.

$B$ : I agree. Spinach tastes good to me as well.

Whenever $B$ may respond with "I agree. Spinach is tasty", he also may respond with "I agree. Spinach tastes good to me as well", and vice versa. $B$ is explicit about expressing his attitude toward spinach; he says that spinach tastes good to him. At the same time, by adding "as well", he makes it plain that he takes $A$ to express a similar attitude when she utters "Spinach is tasty"; thus, $B$ takes $A$ to be saying that spinach is tasty for $A$. The same strategy can be adopted with respect to (1). We might have:

(4) $A$ : Spinach is tasty.

$B$ : I disagree. Spinach does not taste good to me at all.

Whenever $B$ may respond with "I disagree. Spinach is not tasty", he also may respond with "I disagree. Spinach does not taste good to me at all", and vice versa. $B$ is explicit about expressing his attitude toward spinach; he says that it does not taste good to him. He thus reveals that he has understood $A$ 's utterance as expressing something about her own attitude toward spinach; he subsequently tries to make it plain that he is unlike $A$ in this regard. $B$ 's replies show that his (dis)agreement with $A$ is non-doxastic rather than doxastic. $B$ fails to doxastically agree with $A$ in (3) because $B$ and $A$ express different propositions; on the other hand, $B$ non-doxastically agrees with $A$ because they bear the same attitude toward spinach. $B$ fails to 
doxastically disagree with $A$ in (4) because the two express mutually compatible propositions; on the other hand, $B$ non-doxastically disagrees with $A$ because their attitudes toward spinach are mutually incompatible.

Second, further evidence suggesting that taste propositions are contextually enriched is provided by specifically constructed sentences. Assume that someone utters either of the following sentences:

(5) Spinach is tasty, and it is tasty for me.

(6) Spinach is tasty, but it is not tasty for me.

Both sentences sound strange. The second conjunct in (5) is an unnecessary addition because it repeats what is said in the first conjunct. For the air of redundancy to arise, the second conjunct must express the proposition that spinach is tasty for $X$ (where $X$ is an agent), which is precisely what the first conjunct expresses. If the first conjunct was read as expressing the proposition that spinach is tasty, and the second as expressing the proposition that spinach is tasty for $X$, no redundancy would be perceived. By uttering (6), the speaker seems to express something self-contradictory. However, if the first conjunct of (6) expressed the proposition that spinach is tasty, and the second the proposition that spinach is not tasty for $X$, no contradiction would arise. So, if the second conjunct does contradict the first conjunct, the former must express the enriched proposition that spinach is tasty for $X$.

Third, analogously:

(7) Spinach is tasty. I am sure that it is also tasty for other people.

(8) Spinach is tasty. I am afraid, though, that some people do not find it tasty.

When a person utters (7), she is best understood as expressing the proposition that spinach is tasty for $X$ in the first sentence. This is forced by the fact that the second sentence expresses the proposition that $X$ is sure that spinach is also tasty for other people, meaning those who are different from $X$. The reading according to which the first sentence of (7) expresses the proposition that spinach is tasty is unavailable. Were this the case, mentioning other people who are different from $X$ in the second sentence would sound strange. The same applies to (8). The first sentence is best understood as expressing the proposition that spinach is tasty for $X$. This is, again, forced by the second sentence, in which $X$ 's position is contrasted with that of other people. It expresses the proposition that $X$ is afraid that some people do not find spinach tasty, meaning those who are different from $X$. If the first sentence is not taken to express the contextually enriched proposition, there is no point in contrasting $X$ with others.

Finally, take (9) and (10) and compare them with (11) and (12), respectively:

(9) Spinach is tasty, but I dislike it.

(10) Spinach is not tasty, but I like it.

(11) Spinach is tasty, and I like it.

(12) Spinach is not tasty, and I dislike it. 
(9) and (10) are pretty close to being contradictory. ${ }^{11}$ The first conjuncts of (9) and (10) present a certain view that is subsequently refuted by the respective second conjuncts. Since the second conjuncts explicitly refer to the speaker, it should be expected that the first conjuncts also do so, at least implicitly. Otherwise, the air of contradiction would not arise. So the first conjuncts of (9) and (10) are better assumed to express the enriched propositions involving the speaker. The cases of (11) and (12) are a bit different. Both sentences are acceptable. Moreover, when compared with (5), there is no redundancy in (11); the same also holds for (12). The non-redundancy of (11) and (12) can be interpreted semantically, such that the second conjuncts add something new that is not involved in the first. This interpretation is not feasible, though. The second conjunct of (11) is just the negation of the second conjunct of (9); the former could escape being semantically redundant only if the latter did not give rise to contradictoriness in (9). But (9) is contradictory, and so (11) is redundant in the semantic sense. The same holds for (12). An alternative interpretation of the non-redundancy of (11) and (12) is that their second conjuncts are pragmatically non-redundant. If the speaker utters (11) or (12), the second conjunct can be taken as a mere rhetorical strengthening of the position already expressed by the first conjunct. The two conjuncts rhetorically supplement each other because the first puts more stress on the relation toward the object, while the second highlights the person who stands in that relation. Since it is possible to read (11) and (12) as non-redundant in the pragmatic or rhetorical sense, both conjuncts can be taken to express the same proposition, and thus as semantically redundant without any air of inappropriateness.

The above situations strongly suggest that utterances of taste sentences express enriched propositions. Type I situations thus should be viewed as featuring utterances that express enriched propositions containing implicit references to agents. Based on this, Type I situations may hardly feature doxastic disagreements. This conclusion paves the way toward interpreting the disagreements as non-doxastic. Now if this interpretation is adopted, two challenges arise. First, why it seems to us that the disagreement contained in Type I situations is doxastic rather than non-doxastic? This seeming appears to be a self-evident fact, and that is why we need a story that explains it away somehow. Second, if the disagreement contained in Type I situation

${ }^{11}$ Obviously, there are contexts in which such sentences have non-contradictory uses. Consider "Spinach is tasty, but I dislike it because of its color". This is perfectly acceptable. As far as I can see, this is because "(dis)like" is semantically somewhat underspecified. What is meant by (dis)liking is dependent on the context of use. In the above sentence, disliking has something to do with color rather than taste. In (9), on the other hand, it is associated with taste. "Spinach is tasty, but I dislike it" means one thing when it is part of "Spinach is tasty, but I dislike it because of its color" and another thing when it stands alone. So, this case cannot undermine my reasoning in the main text. Observe, incidentally, that "Spinach is tasty, but I dislike it because of its taste" is again contradictory because disliking is depicted in the second conjunct as connected with taste. 
is non-doxastic, how it can be derived from the utterances produced by the speakers involved in such situations? Thus, we need a story about the derivation of nondoxastic disagreements from disagreements that seem to be doxastic.

\section{DOXASTIC DISAGREEMENT EXPLAINED AWAY}

Why it seems that Type I situations contain doxastic rather than non-doxastic disagreements? This question becomes more pressing when we recall the asymmetry between Type I and Type II situations regarding the possibility of using "That is false". As we have seen, the possibility of using this phrase is a hallmark of doxastic disagreement; this is because "that" is used in this phrase as anaphorically referring to a proposition expressed by another speaker's utterance. Thus, why $B$ may intelligibly place "That is false" in front of his utterance in Type I situation, although it would lead to unacceptable results if the phrase were placed in front of his utterance in Type II situation? Unless one is able to provide a satisfactory response to these questions, one cannot claim that the initial Type I situation involves a case of non-doxastic disagreement.

It seems to me that an explanation that would dispel these doubts is available. Let us start with a slightly different problem that is, nevertheless, connected to the above worries: why people choose to say "Spinach is tasty" instead of "Spinach is tasty for me" in certain kinds of situation? Answering to this question gives us a key to finding a reply to the other questions.

The difference between uttering "Spinach is tasty" and "Spinach is tasty for me" lies in their form rather than content, so to speak. Utterances of "Spinach is tasty" do not contain explicit restrictions as regards the ascription of tastiness to spinach, and thus when one utters "Spinach is tasty" one says something that aspires to general validity. Of course, one usually asserts "Spinach is tasty" on the basis of one's own standards of taste and one's assessment whether spinach meets those standards or otherwise; nevertheless, the omission of explicit restrictions indicates the speaker's expectations that her interlocutors will join her in the assessment of spinach's taste (because, for example, the speaker expects that her interlocutors are sufficiently similar to her in relevant respects). When one utters "Spinach is tasty" one expects that she may converge on this point with other people. This is not generally expected in the case of uttering "Spinach is tasty for me". Of course, the utterer of "Spinach is tasty for me" usually does not expect that her interlocutors will converge on the idea that spinach is tasty for her. The speaker just says that spinach is tasty according to her standards without automatically eliciting other people's standpoints on the taste of spinach. Thus, whenever the speaker utters "Spinach is tasty" and "Spinach is tasty for me" she declares that spinach meets her taste preferences; in the former case, however, the speaker usually attempts to present a point that calls for a more general acceptability. 
Based on this, it is rather easy to explain the emergence of disagreement phenomena in Type I situations. When the speaker utters "Spinach is tasty", she expects that her utterance is true not just according to her own standards of taste but also according to some other people's standards. The addressee's answer "I disagree" frustrates these expectations; the general validity of the speaker's utterance is thus rejected on the basis of the addressee's stating otherwise - the addressee advertises his negative attitude toward spinach as a kind of counterexample to the speaker's utterance that aspired for general validity. In other words, the addressee manifests his rejection of the speaker's attempt at making a more general point. The speaker may naturally react with uttering "Fine, but still spinach is tasty for me", in which case she both retains her point as applied to her standards of taste and withdraws her point as applied to other people's taste preferences.

This explanation predicts why "That is false" is acceptable as a response in Type I situations, even though it is not acceptable in Type II situations. If a person encounters a speaker's utterance of "Spinach is tasty", the person assumes that, apart from applying to the speaker's taste preferences, what the utterance says is also expected to apply to the person's standards of taste. And this is what the person intends to reject - by uttering "That is not true", he says that it is not the case that spinach is tasty according to his standards of taste. In saying so, he simply rejects the general validity of the speaker's utterance. It might be observed that if, after saying "That is false", the person continues with saying "Spinach is not tasty", he has to be understood as saying that spinach is not tasty for him (or some other selected person or persons), provided the person is rational. It means that his utterance of "Spinach is not tasty" does not aspire at having such a general applicability as the original speaker's utterance of "Spinach is tasty". This is because the person already knows, on the basis of the speaker's utterance, that the speaker finds spinach tasty and thus that she would not be willing to adopt the contrary view (at least not without further evidence or deliberation).

\section{A DERIVATION OF NON-DOXASTIC DISAGREEMENT}

Now turn to the other question raised in the very end of Section 3. If the disagreement contained in Type I situation is non-doxastic, how it can be derived from the utterances produced by the speakers involved in such situations? I have dealt with this issue rather extensively elsewhere; I thus merely summarize the main results here. ${ }^{12}$

First of all, there is a very close connection between the proposition that spinach is tasty for $A$ and the proposition that A likes the taste of spinach. Whenever the former proposition is true, the latter proposition must be true as well. This is

\footnotetext{
${ }^{12}$ For further details, see Zouhar (2018).
} 
because the property of being tasty for $A$ and the property of having the taste that is liked by $A$ are closely connected in the sense that whichever object instantiates the former property it has to instantiate the latter property as well. ${ }^{13}$ In other words, it is impossible for an object to instantiate the property of being tasty for A without instantiating the property of having the taste that is liked by $A$; and, based on this, it is impossible for the proposition that spinach is tasty for $A$ to be true without it being that case that the proposition that A likes the taste of spinach also is true. In other words, the former proposition implies the latter proposition merely on the basis of there being a necessary and conceptual relation of entailment between them.

Furthermore, if $A$ 's sincere utterance of a suitable sentence (such as "I like the taste of spinach") expresses the proposition that $A$ likes the taste of spinach, $A$ makes clear that she bears a non-doxastic attitude toward spinach, namely the attitude of liking its taste. Now, in a Type I situation, $A$ is supposed to utter "Spinach is tasty", and this utterance is claimed to express the proposition that spinach is tasty for $A$. Based on the fact that this proposition entails the proposition that $A$ likes the taste of spinach and the fact that this proposition describes $A$ 's non-doxastic attitude toward spinach's taste, $A$ succeeds in manifesting her non-doxastic attitude toward spinach by uttering "Spinach is tasty". This result is crucial for portraying the disagreement contained in Type I situations as non-doxastic.

The derivation of the disagreement contained in the initial Type I situation becomes pretty straightforward. Given her sincere utterance of "Spinach is tasty", $A$ manifests her non-doxastic attitude toward spinach. ${ }^{14}$ Witnessing $A$ 's sincere utterance, $B$ recognizes what is her attitude toward spinach; in particular, $B$ recognizes that $A$ finds spinach tasty. This fact about $B$ can be summarized by saying that he takes $A$ 's utterance of "Spinach is tasty" to express the proposition that spinach is tasty to $A$. It also bears noting that $A$ uttered "Spinach is tasty" that contains no explicit restriction regarding the applicability of tastiness to spinach; based on this, $A$ suggests that she intends to present a view about spinach that aspires to being generally valid in the sense presented in the previous section.

Now $B$ realizes that his gustatory response to spinach is not as positive as $A$ 's. He wants to make this obvious by publicly declaring that his attitude toward spinach differs from $A$ 's. With this aim in mind, he utters "Spinach is not tasty", expressing the proposition that spinach is not tasty to $B$. In saying so, $B$ presents two things: first, that his non-doxastic attitude toward spinach's taste is incompatible with $A$ 's attitude, and second, that he rejects $A$ 's attempt at introducing a view about spinach that aspires to general appreciation. In sum, by presenting his non-doxastic attitude,

${ }^{13}$ This relationship between the two properties can be grasped in terms of the notion of requisite that was carefully defined in Duží et al. (2010, pp. $361-367)$. This notion was introduced, for the first time, in Tichý (1979, p. 408).

${ }^{14}$ Assertions that are not sincere are irrelevant and that is why insincere assertions are ignored here. 
$B$ rejects the idea that $A$ 's attitude toward spinach's taste is generally adopted. In so doing, $B$ presents his disagreement with $A$ 's attitude toward spinach's taste. $B$ 's disagreement is constituted by expressing a proposition that involves an attitude toward spinach's taste that is incompatible with $A$ 's. As a result, $B$ shows that he refuses to adopt the same attitude toward the taste of spinach as $A$, and therefore can be said to disagree with $A$ in the non-doxastic sense.

\section{CONCLUSION}

The implicit driving force for the above considerations is the idea that predicates of personal taste are indexical expressions. Indexical expressions express different semantic contents relative to different contexts of utterance. For example, "I" expresses different semantic contents relative to different contexts because it refers to different agents in different contexts (depending on who is the speaker in a given context of utterance). Predicates of personal taste behave similarly - "tasty" is used to express the property of being tasty for $A$ relative to one context of utterance and the property of being tasty for $B$ relative to another context of utterance, for example. In general, different contexts of utterance are used to determine different standards of taste relative to which things are recognized as tasty or otherwise, and that is why the expressed properties may differ across various contexts of utterance.

This approach to predicates of personal taste may be troublesome because it seems to clash with certain obvious phenomena. In particular, people may express disagreements by uttering sentences that involve predicates of taste, and this fact seems to clash with the indexical theory of predicates of personal taste. As people do not disagree with one another provided one utters "I am hungry" and the other responds with uttering "I am not hungry", so people should not be said to disagree with one another if one asserted "Spinach is tasty", meaning to express the proposition that spinach is tasty for $A$, and the other responded with asserting "Spinach is not tasty", meaning to express the proposition that spinach is not tasty for $B$. Nevertheless, it is easy to see that when one person says "I am hungry" and another person says "I am not hungry", they can be said to be in incompatible states regarding their satiety. These states are incompatible in the sense of it being impossible for one person to be in both states at once. Thus, if one sincerely asserts "I am hungry" and another sincerely asserts "I am not hungry", they find themselves to be in the states that resemble disagreement in a very broad sense. A similar approach can be adopted with respect to utterances of sentences about taste. As we have seen, if one person asserts "Spinach is tasty" and another person responds with asserting "Spinach is not tasty", they disagree with one another in a broader sense their disagreement is non-doxastic.

The upshot is that indexicality need not obviate the possibility of disagreement. As a result, the very fact that people may express disagreements about matters of 
personal taste should not be viewed as a decisive argument against indexical theories of predicates of personal taste.

\section{References}

BUEKENS, Filip: Faultless Disagreement, Assertions and the Affective-Expressive Dimension of Judgments of Taste. In: Philosophia, 2011, Vol. 39, pp. 637 - 655.

CLAPP, Lenny: A Non-Alethic Approach to Faultless Disagreement. In: Dialectica, 2015, Vol. 69, pp. $517-550$.

DUŽÍ, Marie - JESPERSEN, Bjørn - MATERNA, Pavel: Procedural Semantics for Hyperintensional Logic: Foundations and Applications of Transparent Intensional Logic. Dordrecht: Springer 2010. $552 \mathrm{pp}$.

EGAN, Andy: There's Something Funny about Comedy: A Case Study in Faultless Disagreement. In: Erkenntnis, 2014, Vol. 79, pp. $73-100$.

GLANZBERG, Michael: Context, Content, and Relativism. In: Philosophical Studies, 2007, Vol. 136 , pp. $1-29$.

GUTZMANN, Daniel: If Expressivism Is Fun, Go for It! In: Subjective Meaning: Alternatives to Relativism. Eds. C. Meier and J. van Wijnberger-Huitink. Berlin: de Gruyter 2016, pp. 21 - 46.

HUVENES, Torfinn Thomesen: Varieties of Disagreement and Predicates of Taste. In: Australasian Journal of Philosophy, 2012, Vol. 90, pp. 167 - 181.

KÖLBEL, Max: Truth without Objectivity. London: Routledge 2002.150 pp.

LASERSOHN, Peter: Context Dependence, Disagreement, and Predicates of Personal Taste. In: Linguistics and Philosophy, 2005, Vol. 28, pp. 643 - 686.

LÓPEZ DE SA, Dan: (2008). Presuppositions of Commonality: An Indexical Relativist Account of Disagreement. In: Relative Truth. Eds. M. García-Carpintero and M. Kölbel. Oxford: Oxford University Press 2008, pp. $297-310$.

MACFARLANE, John: Assessment Sensitivity: Relative Truth and its Applications. Oxford: Oxford University Press 2014. 344 pp.

MARQUES, Teresa - GARCÍA-CARPINTERO, Manuel: Disagreement about Taste: Commonality Presuppositions and Coordination. In: Australasian Journal of Philosophy, 2014, Vol. 92, pp. $701-$ 723.

RICHARD, Mark: When Truth Gives Out. Oxford: Oxford University Press 2008. 184 pp.

SCHAFFER, Jonathan: Perspective in Taste Predicate and Epistemic Modals. In: Epistemic Modality. Eds. A. Egan and B. Weatherson. Oxford: Oxford University Press 2011, pp. 179 - 226.

SILK, Alex: Discourse Contextualism: A Framework for Contextualist Semantics and Pragmatics. Oxford: Oxford University Press 2016. 255 pp.

STEVENSON, Charles Leslie: The Emotive Meaning of Ethical Terms. In: Mind, 1937, vol. 42, pp. $14-31$.

SUNDELL, Timothy: Disagreements about Taste. In: Philosophical Studies, 2011, Vol. 155, pp. $267-288$.

TICHÝ, Pavel: Existence and God. In: The Journal of Philosophy, 1979, Vol. 76, pp. 403 - 420.

WRIGHT, Crispin: Truth and Objectivity. Cambridge, Mass.: Harvard University Press 1992. $262 \mathrm{pp}$.

ZOUHAR, Marián: Conversations about Taste, Contextualism, and Non-Doxastic Attitudes. (Forthcoming in Philosophical Papers, 2018) 